\title{
COR OU ESCOLARIDADE DE PERSONAGENS DE PROPAGANDA? PREFERÊNCIAS ENTRE UNIVERSITÁRIOS
}

\section{COLOR OR EDUCATION OF ADVERTISING CHARACTERS? PREFERENCES AMONG UNDERGRADUATES}

\author{
¿EL COLOR O LA ESCOLARIDAD DE LOS PERSONAJES DE PUBLICIDAD? LAS PREFERENCIAS ENTRE LOS \\ ESTUDIANTES UNIVERSITARIOS
}

\section{RESUMO}

A literatura sobre a avaliação de personagens na propaganda mostra que a identificação de grupos sociais com a etnia varia segundo o objeto investigado. Com o objetivo de contribuir para esse campo foi realizado um survey com 4.200 universitários a fim de identificar suas reações à propaganda de um relógio de pulso. As análises foram feitas com três variáveis dependentes avaliando propaganda, produto e personagem; e três variáveis independentes avaliando a cor do respondente assim como a cor e o nível de escolaridade do personagem na percepção dos respondentes. Os resultados mostraram que a cor do personagem surtiu pouco efeito sobre a avaliação da propaganda e do produto, mesmo entre respondentes da mesma cor de pele. No entanto, a percepção do grau de escolaridade do personagem mostrou-se significativa para explicar as diferentes avaliações do produto e da propaganda.

PALAVRAS-CHAVE Identificação étnica na propaganda, comportamento do consumidor, avaliação de personagem na propaganda, avaliação de produto, avaliação de propaganda.

Sérgio Luiz do Amaral Moretti sergiomoretti@uol.com.br

Professor do Programa de Mestrado e Doutorado em Administração, Universidade Nove de Julho - São Paulo - SP, Brasil

José Mauro da Costa Hernandez jmhernandez@usp.br

Professor do Programa de Pós-Graduação em Administração, Centro Universitário da FEI - São Paulo - SP, Brasil

Patricia Morilha Muritiba pmmuritiba@uninove.br

Professora do Programa de Mestrado e Doutorado em Administração, Universidade Nove de Julho - São Paulo - SP, Brasil

Sérgio Muritiba smuritiba@gmail.com

Professor do Programa de Mestrado e Doutorado em Administração, Universidade Nove de Julho - São Paulo - SP, Brasil

\begin{abstract}
The literature on the evaluation of characters in advertising shows that the identification of social groups with ethnics varies according to the investigated object. With the aim of contributing to this field a survey was carried out with 4200 university students, in order to identify their reactions to a watch advertisement. The analysis considered three dependent variables, evaluating advertising, product and character; and three independent variables, evaluating the color of the respondent as well as the color and the educational level of the character perceived by the respondents. The results showed that the color of the skin of the character had little effect on the evaluation of the advertisement or the product, even among respondents who were of the same skin color. However, the perception of the educational level of the character was significant to explain the different ratings of the advertising and the product. keywords Racial identification in advertising, consumer behavior, assessment of the character in the advertisement, product evaluation, evaluation of
\end{abstract} the advertisement.

Resumen La literatura sobre la evaluación de los caracteres en la propaganda muestra que la identificación de los grupos sociales com etnias varia em función del objeto investigado. Com el objetivo de contribuir para ese campo fue realizado un survey con 4.200 estudiantes universitarios para identificar sus reacciones a la propaganda de un reloj de pulsera. Los análisis fueron hechos con tres variables dependientes, evaluación de la propaganda, del producto y la del personaje; $y$ três variables independientes, la evaluación del cor de lo respondiente, asi como el color y el nível de escolaridade del personage percebidas por los respondientes. Los resultados mostraron que el color del personaje surtió poco efecto sobre la evaluación de la propaganda y del producto, mismo entre respondientes del mismo color de piel. Sin embargo, la percepción del grado de escolaridade del personaje se mostró significativa para explicar las diferentes evaluaciones del producto y de la propaganda.

Palabras clave Identificación étnica en la propaganda, comportamiento del consumidor, evaluación de personaje en propaganda, evaluación de producto, evaluación de propaganda. 


\section{INTRODUÇÃo}

A escolha de personagens (modelos) que se identifiquem tanto com o produto anunciado quanto com os consumidores tem impacto determinante sobre as vendas (REIDENBACH e MCCLEARY, 1983) e, por essa razão, nessa seleção sempre se levam em consideração variáveis como a idade e a etnia, em busca de maior identificação com o público-alvo (CHANG, 2008; GOODMAN, MORRIS, SUTHERLAND, 2008; KOZAR e DAMHORST, 2008). A diversidade étnica dos consumidores e, atualmente, seu maior acesso aos produtos tornam mais relevantes essa questão (CUI, 2001).

No entanto, ainda há muito desacordo sobre como lidar com as diferentes características étnicas dos consumidores (MINOR-COOLEY e BRICE JR, 2007). Para avaliar corretamente o mercado, os profissionais de marketing precisam encontrar suportes teóricos que sustentem seus métodos de acesso aos consumidores. Uma série de estudos sobre esse tema foi realizada, mas a grande maioria toma o cenário norte-americano como base (JONES, 2010), permitindo refletir sobre sua validade para o Brasil.

O país possui um histórico de abolição tardia da escravidão e marginalização da minoria afrodescendente (HOOKER, 2006), e a produção acadêmica tem explorado essa questão em conformidade com sua importância (AZEVEDO, 1966; DA MATTA, 1981, 1990; FERNANDES, 1978; NOGUEIRA, 2007; TELLES, 2003). No entanto, nossa história difere da norte-americana, há uma discussão crescente sobre o nível do preconceito racial e mesmo sobre sua existência (GUIMARÃES, 1999). Pesquisas mostram que cor, status econômico e classe social são fatores de preconceito no país (COMPARATO, 1998) e também que as definições sobre a identificação do público com a etnia em propaganda variam de acordo com a intenção dos pesquisadores (CHEUNG, 1993).

A população de negros e pardos no Brasil, 43\% do total no último censo (INSTITUTO BRASILEIRO DE GEOGRAFIA E ESTATÍSTICA, 2006), representa hoje cerca de 80 milhões de pessoas. Com essa proporção, a nação negra brasileira é maior que a maioria dos países africanos (FERREIRA, 2001), mas sua importância transcende, em larga medida, questões meramente populacionais, adentrando profundamente as relações sociais e, portanto, as representações que os indivíduos fazem das raças com que convivem (TRINDADE, 2008).

Embora exista um grande debate sobre sua existência ou não no Brasil, uma investigação recente em ambiente escolar mostrou discriminação com relação a várias minorias, incluindo as raciais (FUNDAÇÃO INSTITUTO DE PESQUISAS ECONÔMICAS, 2009). Os percentuais encontrados para as diferentes discriminações foram: por gênero, de $38,2 \%$; por deficiência, de $32,4 \%$; socioeconômica, de 25,1\%; étnico-racial, de 22,9\%, e territorial, de 20,6\%. Como se vê, a discriminação está presente nas escolas brasileiras, fato sustentado por $94,2 \%$ da amostra que assumiram exercer algum nível de discriminação. Tal fato é reforçado pela constatação de que 19\% já sofreram bullying, ou seja, algum tipo de hostilidade por serem negros, seguidos de 18,2\% por serem pobres e $17,4 \%$ por serem homossexuais, para citar alguns exemplos (FUNDAÇÃO INSTITUTO DE PESQUISAS ECONÔMICAS, 2009, p. 2).

Uma iniciativa pioneira para o debate sobre o papel dos afrodescendentes na sociedade foi realizada pelo Centro Brasileiro de Informação e Documentação do Artista Negro (Cidan), fundado pela atriz Zezé Mota, em 1984, com o objetivo de discutir a resistência à presença dos afrodescendentes na mídia em geral. Outro marco foi a "Democracia Cordial", pesquisa do Datafolha sobre o preconceito em geral, mas que abriu caminho para a segmentação da questão para áreas determinadas e atraiu a atenção das empresas para o que parecia ser um novo mercado (TURRA e VENTURI, 1995). Uma pesquisa mais abrangente sobre o tema, contudo, ocorreu somente na década de 1990 (GROTTERA, 1995) e mostrou a existência de uma classe média negra brasileira, cerca de sete milhões de pessoas (STROZENBERG, 2008).

A campanha "Onde você guarda o seu racismo?", divulgada entre 2004 e 2006 (HERINGER e LOPES, 2003), mostrou uma improbabilidade estatística de proporções nacionais, já que $87 \%$ dos respondentes acreditavam na existência de racismo no Brasil, entretanto somente $4 \%$ se declaravam racistas. Com o objetivo de ampliar o conhecimento nesse campo de estudo, foi realizado um levantamento com 4.200 jovens universitários de uma instituição de ensino superior de grande porte na cidade de São Paulo, por meio do qual se pretendeu responder às seguintes questões:

- Qual o efeito da cor do personagem sobre a avaliação da propaganda?

- Qual o efeito da escolaridade percebida do personagem sobre a avaliação da propaganda?

O artigo está estruturado da seguinte maneira: o referencial teórico apresenta descobertas anteriores 
sobre a identificação com personagens de propaganda, tanto no Brasil quanto em outros países, bem como as principais teorias que orientam a pesquisa nessa área; a seguir, são apresentados os procedimentos metodológicos do estudo, dando sequência à apresentação dos resultados, sua discussão e conclusões.

\section{TEORIA E HIPÓTESES}

A escolha de personagens de diferentes etnias para propaganda, tema tratado pelo marketing étnico, é o esforço deliberado de atingir um grupo de consumidores, presumivelmente por suas características étnicas únicas (CUI, 2001). Entretanto, embora fartas no mundo acadêmico e cultural no que se refere às abordagens de aspectos antropológicos e sociológicos, as pesquisas relacionadas à propaganda só recentemente ganharam terreno no Brasil. Mesmo assim, refletindo, em geral, o espectro de teorias que buscam explicar por que a maioria da população representada pelos afrodescendentes se encontrou, até recentemente, quase ausente na comunicação comercial (FRY, 2002; MARTINS, 2003; SOUZA, 2005).

São diversos os motivos para a pequena presença de personagens afrodescendentes nas propagandas veiculadas na mídia brasileira. Acevedo e Nohara (2008) analisaram a discriminação contra afrodescendentes, demonstrando, por meio de diversos indicadores, que os retratos mostrados pela mídia são reflexos da discriminação vigente na sociedade brasileira. Do ponto de vista da proporcionalidade em relação à população, os afrodescendentes encontram-se sub-representados, seus papéis são os de menor prestígio - motoristas, empregadas, trabalhadores braçais, favelados (ARAÚJO, 2000; RODRIGUES, 2001), as atividades desempenhadas por eles são frequentemente passivas e os produtos anunciados são sempre de preço barato, e, finalmente, é raro os personagens afrodescendentes aparecerem segurando-os.

Já nos EUA, é comum a utilização de personagens negros, principalmente para a propaganda de artigos esportivos, visto que atletas famosos são frequentemente afrodescendentes. Mesmo nos casos de maior identificação com o personagem, o estudo de Wilson e Sparks (1996) mostrou que existem diferenças na percepção de jovens brancos e negros. Na realidade norte-americana, a questão da diversidade na propaganda assume uma conotação importante devido ao histórico de conflitos entre brancos e negros no país. Por outro lado, a presença dos africanos, hispânicos e asiáticos vem crescendo, especialmente na classe média, e tornando-se cada vez mais valiosa para estudos científicos (WILL, COBB, CHENEY, 2008).

Minor-Cooley e Brice Jr. (2007) identificaram três principais teorias que procuram explicar a identificação com a raça em propagandas. De fato, as teorias quase que se completam na sua busca por explicações para a questão de identificação, seja étnica ou outra. Segundo Cheung (1993), as interpretações sobre a identificação do público com a etnia, em propaganda, variam de acordo com a intenção dos pesquisadores. A primeira delas, chamada de viés interno do grupo (in group bias), foi proposta por Brewer (1979) e sugere que os indivíduos tenderão a favorecer elementos do seu mesmo grupo e que há grande distância social entre estes e os membros externos ao grupo.

A segunda, a teoria da distinção (distinctiveness theory), apresentada por Grier e Deshpandé (2001), mostra que a questão está mais nas diferenças de uma pessoa (ou grupo) para outra (ou outro grupo) do que nas semelhanças. Assim, se a classe social é um fator relevante de diferenciação, a cor pode não ser o principal fator considerado para a identificação com o outro.

A terceira teoria, de acordo com Minor-Cooley e Brice Jr. (2007), é a da acomodação cultural (intercultural accommodation), proposta por Holland e Gentry (1999), para os quais os símbolos culturais - como linguagem, música, arte e vestimentas - e também a presença de personagens da mesma origem étnica influenciam a eficácia da propaganda. De acordo com essa teoria, não é exatamente a cor que influencia a identidade do indivíduo, mas sim um conjunto mais amplo de variáveis culturais, que engloba costumes de uma mesma região ou povo.

Em contrapartida à primeira teoria - viés interno do grupo (in group bias) - Qualls e Moore (1990) apresentaram sua teoria de avaliação polarizada ( $p o-$ larized evaluation), segundo a qual os membros de um grupo tenderão a avaliar os membros externos de maneira extremada, positivamente ou negativamente. Essa teoria foi comprovada em diversos estudos posteriores, como em Martin, Lee e Yang (2004).

\section{Identificação do consumidor com personagens da mesma cor}

Estudos anteriores, internacionais, sobre avaliação da propaganda mostraram que ela pode variar conforme 
a semelhança entre a cor do consumidor e a cor do modelo da propaganda.

Whittler, Calantone e Young (1991) desenvolveram um instrumento para mensurar a identificação dos negros com a cultura africana (afro). Esse seria um fator relacionado com a posterior possibilidade de o negro identificar-se mais com personagens negros do que com personagens brancos em publicidade. Os autores testaram a hipótese de que os negros que se identificam mais fortemente com a cultura afro reagiriam de maneira mais favorável a propagandas com personagens negros do que aqueles que não têm tanta identificação com essa cultura. Seus achados mostraram que os negros com alta ou baixa identificação percebiam-se mais similares aos personagens negros do que aos brancos. Já aqueles com alta identificação com a raça demonstravam preferência acentuada por personagens negros.

Resultado semelhante foi obtido no estudo de Whittler e Spira (2002). Mais uma vez, os negros com alto nível de identificação com a cultura afro foram aqueles que mais intensamente preferiram os personagens negros em propaganda. Esse estudo adicionou outra dimensão ao campo de estudo: a boa avaliação do personagem também fez com que os consumidores avaliassem bem o produto. Em suma, os negros com alta identificação com a raça tenderiam a avaliar melhor os produtos cujos personagens de divulgação fossem negros - estendendo para o produto sua identificação com o personagem de propaganda.

Em uma pesquisa com moradores de uma cidade norte-americana, Qualls e Moore (1990) realizaram um levantamento em que apresentavam diferentes anúncios a 200 pessoas, sendo 100 negras e 100 brancas. Seus resultados apontaram um maior poder explicativo da escolha do anúncio pela teoria do viés interno do grupo. Isso significou que, em território norte-americano, as pessoas tenderam a avaliar melhor personagens de propaganda que possuíam as mesmas características étnicas que elas. Os autores buscaram indícios de avaliação polarizada, adicionalmente aos seus resultados. Sua hipótese era a de que grupos étnicos distintos iriam avaliar o grupo oposto muito melhor ou muito pior. A polarização, dentro dessa teoria, depende da intensidade da diferença de avaliação. Mas isso não se confirmou nos estudos dos autores. Os resultados mostraram simplesmente uma maior identificação com o personagem da mesma etnia, sem ter sido observada grande insatisfação com o personagem de etnia diferente.
Nos anos 1960 e 1970, estudos nos EUA (tais como os de BARBAN e CUNDIFF, 1964; CAGLEY e CARDOZO, 1970; MUSE, 1971; STAFFORD, BIRDWELL, VAN TASSEL, 1970) examinaram a influência da raça do personagem nas tendências de compra do consumidor e indicaram que, embora os sujeitos brancos não reagissem extremamente de maneira negativa aos personagens negros, as reações não eram tão positivas quanto com personagens brancos. Já os consumidores negros preferiam as propagandas com personagens negros, em vez de com brancos. Posteriormente, Whittler (1991) identificou uma série de falhas metodológicas nesses estudos, que deixaram de considerar: 1) características de demanda dos produtos; 2) efeitos de amostragem; 3) problemas em usar propagandas reais e não experimentos, considerando produtos diferentes, e 4) necessidade de uso de grupo de controle.

Os resultados desses estudos permitem elaborar o seguinte conjunto de hipóteses:

\begin{abstract}
H1a: Consumidores brancos, negros ou mulatos/ pardos terão médias diferentes de avaliação da propaganda, significando que a cor do consumidor tem efeito principal sobre a avaliação da propaganda.

H1b: As médias de avaliação da propaganda com personagens brancos, negros ou mulatos/pardos serão diferentes, significando que a cor do personagem tem efeito principal sobre a avaliação da propaganda.
\end{abstract}

H1c: As médias da avaliação da propaganda com personagens brancos, negros ou mulatos/pardos serão diferentes para consumidores brancos, negros ou mulatos/pardos, significando que a interação entre a cor do consumidor e a cor do personagem da propaganda tem efeito sobre a avaliação da propaganda.

Espera-se, nos resultados deste estudo, portanto, que, nos casos em que há semelhança entre a cor do consumidor e a cor do personagem, a propaganda seja mais bem avaliada. Isso comprovaria a teoria da identificação com a cor (MINOR-COOLEY e BRICE JR, 2007) - consumidores brancos, mulatos ou pardos, ou negros tenderiam a preferir personagens da mesma cor que a sua. Como boa parte desses estudos desenvolveu-se no contexto norte-americano, isso leva a questionar sua pertinência para a realidade brasileira, o que o presente estudo testará. 


\section{Identificação do consumidor com personagens com nivel de escolaridade mais alta}

Há indícios, em estudos anteriores, de que a percepção de escolaridade do personagem da propaganda possa ter efeitos sobre a avaliação da peça publicitária, especialmente no caso brasileiro.

O estudo de Almeida e Young (2007), no Brasil, investigou se a percepção sobre a cor mudaria segundo o prestígio da profissão. Assim, um afrodescendente teria melhor avaliação, caso estivesse de terno e classificado como advogado, por exemplo. Sua metodologia consistiu em mostrar um conjunto de nove fotos de brancos, pardos e negros vestidos com roupas de diferentes profissões de maneira combinada e averiguar a avaliação da amostra sobre qual raça combinava melhor com qual profissão. Os resultados mostraram que, embora personagens negros e pardos tenham sido avaliados negativamente, a avaliação deles melhorou conforme o grau de escolaridade percebido (identificado pela vestimenta utilizada) no contexto da pesquisa.

Internacionalmente, no entanto, os estudos de Brumbaugh (2009) mostraram que a identificação com a raça foi maior do que a identificação com o gênero ou a profissão do personagem de propaganda, tanto com indivíduos de cor branca quanto com negros. No entanto, eles testaram anúncios culturalmente ambíguos - misturando elementos relacionados com a etnia, tais como um personagem branco usando roupas culturalmente africanas, entre outras misturas de elementos étnicos. Nesse caso, diferentemente do que ocorreu quando a cor do personagem foi isolada, os indivíduos brancos, assim como os negros, tiveram identificação com personagens diversos, sem adotar um padrão.

No Brasil, é possível indagar se o grau de escolaridade percebido do personagem de uma propaganda tem efeitos sobre a avaliação da propaganda, levando às hipóteses adicionais:

H2a: As médias de avaliação da propaganda com personagens de escolaridade alta e baixa serão diferentes, significando que a escolaridade do personagem tem efeito principal sobre a avaliação da propaganda.

H2b: Consumidores brancos, negros e mulatos/ pardos terão médias diferentes de avaliação de propagandas com personagens brancos, negros e mulatos/pardos e de escolaridades diferentes (alta ou baixa), significando que a interação entre a cor do consumidor, a cor do personagem e a escolaridade percebida do personagem tem efeito sobre a avaliação da propaganda.

Nesse caso, pretende-se verificar se, quando se considera também a escolaridade do personagem da propaganda, esta influencia a variação da avaliação da propaganda.

\section{PROCEDIMENTOS METODOLÓGICOS}

Este estudo apresenta os resultados de um levantamento com estudantes universitários da cidade de São Paulo. Os sujeitos eram alunos de graduação da maior universidade privada do Estado de São Paulo e a terceira maior do país.

\section{Amostragem}

A população do estudo foi estimada em 100 mil indivíduos, que são o total estimado de alunos da instituição na época da coleta, realizada em todos os cursos de graduação oferecidos. Todos os integrantes do grupo de 100 mil alunos foram convidados a participar por meio do envio de e-mails individuais, o que supõe uma intenção de pesquisa censitária. No entanto, apesar do fato de que qualquer membro da população teve a mesma chance de participar do estudo, aqueles que o responderam o fizeram voluntariamente, o que configura uma limitação da amostra pelo viés de não resposta. Retornaram como amostra do estudo um total de 4.200 respostas, sendo 4.047 consideradas válidas. A magnitude das respostas gerou uma amostra significativa, cujo erro amostral calculado, considerando-se a população finita de 100 mil indivíduos com média e desvio padrão desconhecidos (BARBETTA, REIS, BORNIA, 2004), foi de $\mathrm{E}_{0}= \pm 0,015$, o que a valida como uma boa amostra para o estudo, devido ao seu tamanho. Trata-se, portanto, de uma amostra na qual não houve controle sobre o perfil dos indivíduos que responderam, uma limitação importante. Sobre o perfil da amostra, quando se conduz uma pesquisa com diferenças entre grupos, não é a característica probabilística da amostra o mais importante, mas sim a quantidade de indivíduos em cada grupo, que precisa ser suficiente para atender as premissas da técnica escolhida (AMEDEO, GOLLEDGE, STIMSON, 2009), item que será explorado adiante. 
O perfil dos respondentes abrangeu ampla faixa etária, incluindo alunos acima dos 25 anos de idade, predominantemente de classes média ou média baixa. A amostra de estudantes universitários contou com proporções uniformes de respondentes do sexo feminino $(51,7 \%)$ e masculino $(48,3 \%)$. O fato de a instituição particular escolhida ser voltada a alunos de classes média e média baixa pôde ser notado pelo grau de instrução do chefe da família - apenas 17,3\% dos chefes de família possuíam superior completo. Os demais $82,7 \%$ dividiam-se entre ensino médio completo $(49,3 \%)$, fundamental completo/médio incompleto $(15,6 \%)$ e fundamental incompleto $(17,8 \%)$.

\section{Procedimentos de coleta}

Quanto à coleta de dados, os respondentes foram convidados a participar por um e-mail que informava o endereço a ser acessado por meio de uma senha, para preencher o questionário hospedado em questionpro.com. Os participantes receberam um termo de consentimento informando riscos e benefícios da participação na pesquisa. Para incentivar a resposta, foi oferecida uma premiação: sorteio de um computador e dois pen drives. A resposta ao questionário eletrônico levava, aproximadamente, 15 minutos.

Os participantes foram direcionados a avaliar uma propaganda de relógios tipo $р о p-u p$ a ser veiculada na internet. Inicialmente, responderam a algumas perguntas de classificação e, a seguir, durante 30 segundos, viram uma página de uma loja eletrônica e a propaganda do relógio. Para não influenciar as respostas, a propaganda não continha a marca do relógio. Foram apresentadas variações de personagens negros, brancos e mulatos. Também se isolou a variável gênero, já que foram apresentados personagens do sexo masculino ou feminino em conformidade com o sexo do respondente, de modo que mulheres eram expostas a personagens do sexo feminino e homens, a personagens do sexo masculino. A variação na cor do modelo da propaganda foi escolhida randomicamente.

\section{Variáveis e medidas}

A pesquisa testou o efeito de três fatores, ou variáveis de tratamento, sobre a avaliação da propaganda - variável dependente. Posteriormente, foi testado também o efeito desses três fatores sobre a avaliação do personagem da propaganda.

A variável dependente "avaliação da propaganda" foi mensurada por meio de uma medida que combinou respostas para seis perguntas, representadas pela escala Likert de seis pontos, conforme o grau de concordância do respondente com as assertivas. A validade interna das medidas de avaliação da propaganda foi satisfatória, com alpha de Cronbach de $\alpha=0,808$ e cargas fatoriais com valores superiores a 0,5 .

Já com relação às variáveis de tratamento, a cor do respondente e a cor do personagem poderiam assumir três tratamentos: branca, mulata/parda e negra. Considerou-se a cor do personagem percebida pelo respondente. Cada respondente foi exposto a somente uma das três cores de personagem (branca, mulata/ parda ou negra) e precisou responder a uma questão sobre qual era a cor do personagem da propaganda. Esses dados foram cruzados com a cor real do personagem, tendo sido excluídos os casos em que não houve consenso entre a cor real e a cor respondida (por exemplo, o personagem era negro e foi apontado pelo respondente como branco).

A escolaridade do personagem aceitava valores de 1 a 6 , conforme o grau de escolaridade que o respondente acreditava que o personagem tinha, entre eles: fundamental incompleto, fundamental completo, médio completo, superior completo e pós-graduação. Essa variável foi recodificada em dois grupos de tratamento: baixa escolaridade e alta escolaridade.

\section{Procedimentos de análise}

A análise dos dados foi feita mediante uma análise de variância (Anova) fatorial, também chamada de Two-Way Anova, utilizando-se, para o cálculo, o SPSS. Essa técnica é adequada quando são examinadas diferenças entre grupos de indivíduos, considerando-se mais de um fator ou variável de tratamento. Ela traz dois tipos de resultados: testa os efeitos principais dos fatores, analisados individualmente sobre a variável dependente, e testa o efeito de interação entre os fatores, representando o efeito que a combinação de dois ou mais fatores tem sobre a variável dependente.

Foram respeitadas as premissas principais desse tipo de Anova, sendo (O'ROURKE, HATCHER, STEPANSKI, 2005): nível de medida - a variável dependente é intervalar e as variáveis de tratamento são categóricas; independência das observações - as amostras dos grupos das variáveis de tratamento são independentes; e a amostra é randomicamente extraída da população, apesar da limitação do viés de não resposta, e cada grupo analisado das variáveis 
de tratamento contém mais de 30 indivíduos, o que é suficiente para atender à premissa da normalidade.

\section{APRESENTAÇÃO DOS RESULTADOS}

\section{Efeito da cor do consumidor e da cor do personagem sobre a avaliação da propaganda}

O primeiro conjunto de hipóteses de pesquisa refere-se a três análises: a influência da cor do consumidor (branca, negra e mulata/parda) sobre a avaliação da propaganda; a influência da cor do personagem (branca, negra e mulata/parda) sobre a avaliação da propaganda e a interação dessas duas variáveis independentes (cor do consumidor e cor do personagem) sobre a avaliação da propaganda. Para testar esse conjunto de hipóteses, foi realizada uma análise de variância fatorial (Two-Way Anova) considerando-se a variável dependente "avaliação da propaganda", medida de 1 a 6, e os fatores "cor do respondente" e "cor do personagem". Os resultados obtidos por meio da Anova fatorial, com dois fatores, estão expressos na Tabela 1.

A Tabela 1 mostra, primeiramente, que o efeito principal da cor do consumidor (cor do respondente) sobre a avaliação da propaganda é significante a sig $<0,05$ para $\mathrm{F}_{(2,3715)}=6,765, \mathrm{p}=0,001$. Isso significa que consumidores brancos, negros e mulatos/pardos tiveram médias diferentes de avaliação da propaganda, confirmando a hipótese de pesquisa H1a.

Já a cor do personagem não teve efeito principal sobre a avaliação da propaganda, não confirmando a hipótese de pesquisa $\mathrm{H1b}$, para $\mathrm{F}_{(2,3715)}=0,298$, $\mathrm{p}=0,810$. Isso mostra que a avaliação da propaganda obteve médias semelhantes, independentemente da cor do personagem de propaganda apresentado, um achado interessante diante da literatura internacional analisada. Isso implica que personagens de cores diferentes não tiveram impacto na opinião dos respondentes sobre a propaganda. Esse resultado contraria as expectativas do estudo, orientado pelos resultados de pesquisas anteriores (WHITTLER, CALANTONE, YOUNG, 1991; WHITTLER e SPIRA, 2002).

Contrariamente ao predito na hipótese $\mathrm{H} 1 \mathrm{c}$, não houve efeito de interação entre a cor do responden-

\section{Tabela 1 - Resultados da Anova fatorial - H1 Testes de efeitos subjetivos}

\begin{tabular}{|l|c|c|c|c|c|c|c|}
\hline \multicolumn{1}{|c|}{ Fonte da variância } & SQ & gl & MQ & F & P & Eta & $\begin{array}{c}\text { Poder } \\
\text { observado }\end{array}$ \\
\hline Intercepto & 13126,3 & 1 & 13126,300 & 9279,000 & 0,000 & 0,714 & 1,000 \\
\hline A Cor respondente & 19,141 & 2 & 9,570 & 6,765 & 0,001 & 0,004 & 0,919 \\
\hline B Cor do personagem & 0,597 & 2 & 0,298 & 0,211 & 0,810 & 0,000 & 0,083 \\
\hline Interação A.B & 0,859 & 4 & 0,215 & 0,152 & 0,962 & 0,000 & 0,082 \\
\hline Erro & 5255,330 & 3715 & 1,415 & & & & \\
\hline
\end{tabular}

Variável dependente: avaliação da propaganda (valores de 1 a 6)

Tabela 2 - Média de avaliação da propaganda com relação à cor do respondente

\begin{tabular}{|l|c|c|c|c|}
\hline \multicolumn{1}{|c|}{ Cor do respondente } & Média & $\begin{array}{l}\text { Desvio } \\
\text { padrão }\end{array}$ & \multicolumn{2}{|c|}{ 95\% Intervalo de confiança } \\
\hline 1 branca & 3,290 & 0,025 & 3,241 & 3,339 \\
\hline 2 mulata ou parda & 3,437 & 0,038 & 3,362 & 3,513 \\
\hline 3 negra & 3,510 & 0,096 & 3,322 & 3,698 \\
\hline
\end{tabular}

Variável dependente: avaliação da propaganda (média de 1 a 5) 
te e a cor do personagem, dado que os resultados da Anova não foram significantes para $\mathrm{F}_{(4,3715)}=0,152$, $\mathrm{p}=0,962$. Isso significa que, ao contrário das teorias de identificação com a cor, consumidores brancos não tiveram médias maiores de avaliação da propaganda quando o personagem da propaganda era branco; o mesmo não ocorreu com consumidores negros e personagens negros, ou consumidores mulatos/pardos e personagens mulatos/pardos.

O efeito da cor do respondente sobre a avaliação da propaganda deve-se principalmente ao fato de que os respondentes brancos deram notas menores para a propaganda do que os mulatos e negros (Tabela 2).

Esses resultados mostram que, embora a cor do respondente influencie a avaliação da propaganda, esse efeito não é moderado pela cor percebida do personagem. Tal influência dá-se principalmente porque os respondentes brancos atribuíram notas menores para a avaliação da propaganda. Contrariamente à teoria de identificação com a raça (MINOR-COOLEY e BRICE JR, 2007), a cor percebida do personagem não mostrou efeito significativo sobre a avaliação da propaganda.

\section{Efeito do grau de instrução percebido do personagem sobre a avaliação da propaganda}

O segundo conjunto de hipóteses de pesquisa (H2a e H2b) incluía na análise, além da cor do consumidor e da cor do personagem da propaganda, o grau de escolaridade percebido desse personagem, e os efeitos dessas três variáveis independentes sobre a dependente avaliação da propaganda.

Para testar esse conjunto de hipóteses, foi utilizada novamente a Anova fatorial, mas agora com três fatores: cor do consumidor, expressa em branca, negra e mulata/parda; cor do personagem, expressa em branca, negra e mulata/parda, e escolaridade percebida do personagem, expressa em alta ou baixa. Os resultados da Anova fatorial com três fatores, com a variável dependente "avaliação da propaganda", estão descritos na Tabela 3.

A técnica utilizada testa sete hipóteses nulas. Primeiramente, ela testa o efeito principal de cada um dos três fatores, cor do respondente, cor do personagem e instrução percebida do personagem, sobre a avaliação da propaganda. Depois, testa os efeitos de interação desses fatores, dois a dois, e dos três fatores em conjunto.

Pode-se perceber, pela Tabela 3, que, em termos de significância de 0,05 , a única hipótese nula rejeitada na técnica foi a que testa o efeito principal da instrução percebida do personagem sobre a avaliação da propaganda. Esse efeito é significante para $\mathrm{F}_{(5,3674)}=13,282, \mathrm{p}=0,00$. Isso mostra que a avaliação da propaganda recebeu notas diferentes para diferentes percepções de escolaridade do personagem da propaganda, aceitando-se a hipótese de pesquisa H2a deste estudo: a instrução percebida do personagem tem efeito principal sobre a avaliação da propaganda.

\section{Tabela 3 - Resultados da Anova fatorial - H2 Testes de efeitos subjetivos}

\begin{tabular}{|l|c|c|c|c|c|c|}
\hline \multicolumn{1}{|c|}{ Fonte da variância } & SQ & G & MQ & F & P & $\begin{array}{c}\text { Poder } \\
\text { Eta }\end{array}$ \\
\hline observado \\
\hline Intercepto & 2112,557 & 1 & 2112,557 & 1554,431 & 0,000 & 0,297 \\
\hline A Cor do respondente & 7,216 & 2 & 3,608 & 2,655 & 0,070 & 0,001 \\
\hline B Cor do personagem & 0,09698 & 2 & 0,04849 & 0,036 & 0,965 & 0,000 \\
\hline C Instrução percebida do personagem & 90,256 & 5 & 18,051 & 13,282 & 0,000 & 0,018 \\
\hline Interação A.B & 3,023 & 4 & 0,756 & 0,556 & 0,695 & 0,001 \\
\hline Interação A.C & 8,652 & 9 & 0,961 & 0,707 & 0,703 & 0,000 \\
\hline Interação B.C & 13,797 & 10 & 1,380 & 1,015 & 0,428 & 0,003 \\
\hline Interação A.B.C & 27,422 & 17 & 1,613 & 1,187 & 0,266 & 0,003 \\
\hline Erro & 4993,168 & 3674 & 1,359 & & 0,549 \\
\hline
\end{tabular}

Variável dependente: avaliação da propaganda (valores de 1 a 6) 
De fato, a média de avaliação da propaganda aumenta proporcionalmente ao grau de instrução do personagem, como se pode verificar na Tabela 4 .

É interessante notar que os demais fatores - cor do consumidor e cor do personagem - não têm efeito principal significativo quando se inclui a escolaridade no modelo testado. A cor do consumidor havia apresentado um efeito principal significante na Anova apresentada anteriormente (Tabela 1), mas, com a inclusão do fator escolaridade, o efeito da cor do consumidor (cor do respondente) não é significante para $\mathrm{F}_{(2,3674)}=2,655, \mathrm{p}=0,07$. Incluindo-se a escolaridade, as médias de avaliação da propaganda são estatisticamente iguais para consumidores brancos, negros e mulatos/pardos.

Da mesma forma como ocorreu no teste da hipótese $\mathrm{H} 1 \mathrm{~b}$, a cor do personagem não apresentou efeito principal significante sobre a avaliação da propaganda, incluindo-se o grau de instrução percebido, a $\mathrm{F}(2,3674)=0,036, \mathrm{p}=0,965$. Isso mostra que a cor do personagem não exerceu efeito sobre as diferenças na avaliação da propaganda.

Os efeitos de interação também não apresentaram resultados significantes, destacando-se o efeito de interação entre a cor do consumidor, a cor do personagem e a escolaridade percebida do personagem, ao qual se referia a hipótese H2b. Esse efeito não foi significante a $\mathrm{F}_{(17,3674)}=1,187, \mathrm{p}=0,26$, levando à não aceitação da hipótese de pesquisa $\mathrm{H} 2 \mathrm{~b}$.

Esses resultados indicam que, no Brasil, existe a possibilidade de discriminação social. Isso levaria à proposição de que os potenciais consumidores tenderiam a identificar-se mais com personagens de maior grau de escolaridade. Na amostra deste estudo, composta por estudantes universitários, essa identificação poderia assumir um efeito ainda mais intenso.

\section{Discussão}

Como mostrado anteriormente, os resultados indicam que a avaliação da propaganda e do produto por consumidores de diferentes etnias não variou devido ao efeito da cor do personagem da propaganda. O que se verificou foi que os respondentes brancos tenderam a avaliar propaganda e produto mais criticamente do que os demais. Tal avaliação, no entanto, não se deveu à cor do personagem, mas provavelmente a preferências individuais desse grupo de respondentes, não explicadas pela presente análise. Isso levou a aceitar a hipótese H1a, que previa que a cor do consumidor tem efeito principal sobre a avaliação da propaganda.

Como a cor do personagem da propaganda não exerceu efeito principal sobre a avaliação desta, não foi possível aceitar a hipótese de pesquisa H1b, que previa que a cor do personagem teria efeito sobre a avaliação da propaganda, levando propagandas com personagens brancos, negros e mulatos/pardos a terem médias de avaliação diferentes.

Esse resultado traz uma novidade em relação aos estudos anteriores, que mostraram identificação de cor entre consumidores e personagens de propaganda, notadamente aqueles apresentados na literatura, como Minor-Cooley e Brice Jr. (2007), Qualls e Moore (1990), Whittler (1991), Whittler, Calantone e Young (1991) e Whittler e Spira (2002).

Se, na sociedade norte-americana, esse efeito apareceu fortemente em pesquisas realizadas, no caso da população deste estudo, no contexto brasileiro e mais específico da cidade de São Paulo, isso não se verificou. Talvez a sociedade brasileira sofra mais os efeitos da desigualdade social no país do que problemas de discriminação pela cor. Nesse sentido, alguns autores têm trabalhado com a ideia de que, no Brasil, possa haver discriminação social. Pessoas de classes sociais mais baixas tenderiam a ser preteridas na sociedade. A discriminação social é um conceito mais amplo, mas que também engloba a questão da educação, já que, no Brasil, muitas vezes, as camadas mais altas da sociedade têm acesso a melhores condições educacionais. Assim, a educação seria um indicador social importante na sociedade brasileira.

Neste estudo, observou-se que o grau percebido de instrução do personagem, ao contrário de sua cor, explicava variações na avaliação da propaganda e do produto. Mesmo no caso da avaliação do personagem, que havia tido um efeito de cor, esse efeito desapareceu quando se considerou conjuntamente o seu grau de instrução. Isso permitiu aceitar a hipótese de pesquisa $\mathrm{H} 2 \mathrm{a}$, que previa que a escolaridade percebida do personagem da propaganda teria efeito sobre a avaliação desta. De fato, pôde-se notar que, conforme aumentou a percepção de escolaridade do personagem, maior foi a nota da propaganda (Tabela 4). A interação entre as três variáveis - cor do consumidor, cor do personagem e escolaridade percebida do personagem - não se mostrou, contudo, significativa, levando à não aceitação da hipótese H2b.

A aceitação da hipótese H2a tem implicações sobre a compreensão racial no caso brasileiro, já que, ao contrário de pesquisas internacionais, mostra que 


\section{Tabela 4 - Média de avaliação da propaganda com relação ao grau de instrução percebido}

\begin{tabular}{|l|c|c|c|c|}
\hline \multicolumn{1}{|c|}{$\begin{array}{c}\text { Qual o grau de instrução } \\
\text { desta pessoa? }\end{array}$} & Média & $\begin{array}{c}\text { Desvio } \\
\text { padrão }\end{array}$ & \multicolumn{2}{|c|}{$\begin{array}{c}\text { 95\% Intervalo de confiança } \\
\text { Limite inferior }\end{array}$} \\
\hline 1 ensino fundamental & 2,730 & 0,221 & 2,297 & 3,162 \\
\hline 2 ensino médio & 2,927 & 0,091 & 2,750 & 3,105 \\
\hline 3 cursando faculdade & 3,525 & 0,042 & 3,443 & 3,607 \\
\hline 4 terminou faculdade & 3,515 & 0,123 & 3,274 & 3,755 \\
\hline 5 cursando/terminou pós- graduação & 3,976 & 0,231 & 3,523 & 4,428 \\
\hline
\end{tabular}

Variável dependente: avaliação da propaganda

a educação tem maior efeito sobre preferências do que a cor das pessoas. Esse resultado vem ao encontro de estudos anteriores de Almeida e Young (2007), Brumbaugh (2009) e da distinctiveness theory de Grier e Deshpandé (2001). Esses autores mostraram que interferências de avaliação não são exclusividade da cor ou da etnia, e sim de fatores como educação, o caso desse estudo. É preciso ressaltar que os resultados deste estudo foram obtidos na cidade de São Paulo. Outras realidades podem e devem ser observadas em diferentes regiões brasileiras, já que o Brasil é um país de expressiva diversidade cultural.

Outro efeito que pode estar relacionado aos resultados obtidos foi o fato de o survey ter sido feito com estudantes universitários. Mais do que a educação, no caso, observa-se, talvez, a identificação dos estudantes com pessoas na mesma condição que a sua.

Tomadas as devidas proporções, o estudo atual implica que profissionais de marketing podem levar em conta características sociais mais do que raciais ao elaborarem propagandas de produtos, no caso brasileiro. Isso pode influenciar, inclusive, a maior presença de negros nas propagandas, que ainda é pequena no Brasil.

\section{CONSIDERAÇÕES FINAIS}

O presente estudo apresentou os resultados de um survey com jovens universitários que visou identificar suas reações à propaganda de um relógio de pulso na qual variava apenas o personagem que apresentava o produto, em termos de cor, idade e nível educacional sugerido.

Os resultados mostraram que a cor da pele não influencia a avaliação nem da propaganda, nem do produto. Para o Brasil, o fato de os respondentes brancos não terem avaliado muito negativamente os personagens negros e mulatos pode representar um indício da sua valorização na sociedade (BORGES, MEDEIROS, D’ADESKY, 2002).

Essas descobertas, potencializadas pelo atual crescimento da classe $\mathrm{C}$, indicam a necessidade de prosseguir com essa linha de estudos e averiguar se a maior presença na mídia, e no dia a dia de toda a sociedade, de negros e pardos leva a avaliações mais positivas desse segmento da população. Dentro, ain$\mathrm{da}$, dessa linha, a crescente presença da classe $\mathrm{C}$ nas universidades de todo o país oferece uma excelente oportunidade para se investigar mais profundamente a influência da escolaridade na propaganda. Os dados parecem indicar que existe maior identificação dos indivíduos com personagens de classe socioeconômica semelhante à deles.

O resultado de que a escolaridade percebida do personagem exerceu efeito sobre a avaliação da propaganda condiz com uma tendência apontada por Minor-Cooley e Brice Jr. (2007) de suavização das diferenças raciais e das fronteiras culturais. Para os autores, nos censos realizados, cada vez mais as pessoas vêm tendo dificuldades em apontar de qual raça fazem parte. Isso configura uma situação de globalização das fronteiras culturais. Nesse ambiente, o maior desafio para os profissionais de marketing é atingir os membros de grupos culturalmente diferentes com sucesso.

No Brasil, essa tendência pode ter ainda mais impacto. O país é conhecido por ser formado por diferentes etnias e procedências, desde os portugueses colonizadores, os índios que já habitavam a região e os africanos que vieram como escravos, até os imigrantes de diferentes partes da Europa e da Ásia que vieram trabalhar nas lavouras e forma- 
ram agrupamentos culturais no país. Em ambientes multiculturais, é observado que os consumidores raramente se identificam como parte de um grupo ou categoria étnica específica (JAMAL, 2003). Nessa linha, pode residir uma das explicações para os achados desta pesquisa.

Podem-se apontar duas limitações da pesquisa que devem ser evitadas em futuros estudos: a simulação da propaganda por meio de desenhos pode ser contornada lançando mão de fotos de pessoas reais e um controle sobre a cor do respondente pode ser feito, já que, no presente caso, foi deixada para ele a responsabilidade de se classificar entre uma das três opções oferecidas.

A contribuição deste estudo para a academia foi trazer a questão da etnia para uma posição de destaque e oferecer insights para outros estudos que lhe deem a importância merecida, pelo menos na área da administração. O segmento de negros e pardos em ascensão na sociedade brasileira não pode e não deve ser negligenciado. Para o campo gerencial, a contribuição foi proporcionar novas possibilidades de reflexão sobre os métodos de comunicação com esse crescente e importante segmento.

Duas aplicações teóricas são advindas das contribuições mencionadas acima: a teoria estrangeira não se aplica à realidade brasileira e a discriminação social, nela considerando-se a percepção de educação, deve ser mais bem explorada nos estudos desse campo. Ambas as variantes têm implicações acadêmicas e gerenciais que devem ser consideradas em futuros estudos.

Finalmente, uma lista de futuras pesquisas pode ser sugerida: realizar testes com pessoas reais em vez de desenhos, estabelecer critérios de controle para a cor do respondente, acrescentar amostras que incluam população não universitária e utilizar sugestões para o personagem que remetam o respondente para além da percepção do nível educacional.

\section{REFERÊNCIAS}

ACEVEDO, C; NOHARA, J. Interpretações sobre os retratos dos afrodescendentes na mídia de massa. Revista de Administração Contemporânea (RAC), edição especial, p. 119-146, 2008.

ALMEIDA, A; YOUNG, C. A cabeça do brasileiro. São Paulo: Record, 2007.
AMEDEO, D; GOlledGe, R. G; STIMSON, R. J. Person-environment behavior research: investigating activities and experiences in spaces and environments. New York: The Guilford Publications, 2009.

ARAÚjO, J. A negação do Brasil: o negro na telenovela brasileira. São Paulo: Senac, 2000.

AZEVEDO, T. Cultura e situação racial no Brasil. Rio de Janeiro: Civilização Brasileira, 1966.

BARBAN, A. M; CUNDIFF, E. W. Negro and white response to advertising stimuli. Journal of Marketing Research, v. 1, n. 4, p. 53-56, 1964.

BARBETTA, P. A; REIS, M. M; BORNIA, A. Estatística para cursos de engenharia e informática. São Paulo: Atlas, 2004.

BORGES, E; MEDEIROS, C. A; D'ADESKY, J. Racismo, preconceito e intolerância. São Paulo: Atual, 2002.

BREWER, M. In-group bias in the minimal intergroup situation: a cognitive-motivational analysis. Psychological Bulletin, v. 86, n. 2, p. 307-324, 1979.

BRUMBAUGH, A. M. Why do I identify with thee? Let me count three ways: how ad context influences race-based character identification. Psychology and Marketing, v. 26, n. 11, p. 970-986, 2009.

CAGLEY, J; CARDOZO, R. White response to integrated advertising. Journal of Advertising Research, v. 10, n. 2, p. 35-39, 1970.

CHANG, C. Chronological age versus congnitive age for younger consumers: implications for advertising persuasion. Journal of Advertising, v. 37, n. 3, p. 19, 2008.

CHEUNG, Y. Approaches to ethnicity: clearing roadblocks in the study of ethnicity and substance use. Substance Use E Misuse, v. 28, n. 12, p. 1209-1226, 1993.

COMPARATO, F. K. O princípio da igualdade e a escola. Cadernos de Pesquisa, n. 104, p. 47-57, 1998.

CUI, G. Marketing to ethnic minority consumers: a historical journey (1932-1997). Journal of Macromarketing, v. 21, n. 1, p. 23, 2001.

DA MATTA, R. Relativizando: uma introdução à antropologia social. Petrópolis: Vozes, 1981.

DA MATTA, R. Carnavais, malandros e heróis. Rio de Janeiro: Guanabara, 1990.

FERNANDES, F. A integração do negro na sociedade de classes. São Paulo: Ática, 1978. 
FERREIRA, R. A. Olhares negros: estudo da percepção crítica de afrodescendentes sobre a imprensa e outros meios de comunicação. 2001. 2 v. 273 p. Tese de Doutorado, Escola de Comunicações e Artes, Universidade de São Paulo, São Paulo, 2001.

FRY, P. Estética e política: relações entre "raça", publicidade e produção da beleza no Brasil. In: GOLDENGERG, M. O. (Ed). $N u$ E vestido: dez antropólogos revelam a cultura do corpo carioca. Rio de Janeiro: Record, 2002. p. 303-326.

FUNDAÇÃO INSTITUTO DE PESQUISAS ECONÔMICAS. Pesquisa sobre preconceito e discriminação no ambiente escolar. São Paulo, 2009.

GOODMAN, J. R; MORRIS, J. D; SUTHERLAND, J. C. Is beauty a joy forever? Young women's emotional responses to varying types of beautiful advertising models. Journalism and Mass Communication Quarterly, v. 85, n. 1, p. 147-168, 2008.

GRIER, S; DESHPANDÉ, R. Social dimensions of consumer distinctiveness: the influence of social status on group identity and advertising persuasion. Journal of Marketing Research, v. 38, n. 2, p. 216-224, 2001.

GROTTERA. Qual é o pente que te penteia: o perfil do consumidor negro no Brasil. Relatório de Pesquisa,1995.

GUIMARÃES, A. S. A. Racismo e antirracismo no Brasil. São Paulo: FUSP, 1999.

HERINGER, R; LOPES, S. A. Sonhar o futuro, mudar o presente: diálogos pela inclusão racial no Brasil. Rio de Janeiro: Ibase, 2003.

HOLLAND, J; GENTRY, J. Ethnic consumer reaction to targeted marketing: a theory of intercultural accommodation. Journal of Advertising, v. 28, n. 1, p. 65-77, 1999.

HOOKER, J. Inclusão indígena e exclusão dos afrodescendentes na América Latina. Tempo Social: Revista de Sociologia da USP, v. 18, n. 2, p. 89-111, 2006.

INSTITUTO BRASILEIRO DE GEOGRAFIA E ESTATÍSTICA. Indicadores IBGE: o mercado de trabalho segundo a cor ou raça - pesquisa mensal de emprego (Recife, Salvador, Belo Horizonte, Rio de Janeiro, São Paulo e Porto Alegre). Rio de Janeiro: IBGE, 2006.
JAMAL, A. Marketing in a multicultural world. European Journal of Marketing, v. 37, n. 11/12, p. 1599-1620, 2003.

JONES, V. It's not black and white: advertising and race in cultural context. Journal of Global Marketing, v. 23, n. 1, p. 45-64, 2010.

KOZAR, J. M; DAMHORST, M. L. Older women's responses to current fashion models. Journal of Fashion Marketing and Management, v. 12, n. 3, p. 338-350, 2008.

MARTIN, B. A. S; LEE, C. K.-C; YANG, F. The influence of ad model ethnicity and self-referencing on attitudes. Journal of Advertising, v. 33, n. 4, p. 27-37, 2004.

MARTINS, J. Negro não toma sorvete? Um estudo sobre a identidade do negro na comunicação publicitária da Revista "Raça Brasil”. 2003. 141 f. Dissertação de Mestrado, Programa de Pós-Graduação em Comunicação, Escola de Comunicação, Universidade Federal do Rio de Janeiro, Rio de Janeiro, 2003.

MINOR-COOLEY, D; BRICE JR, J. Please check the appropriate box: the problems with ethnic identification and its potential in cross-cultural marketing. Academy of Marketing Science Review, v. 11, n. 9, p. 1-11, 2007.

MUSE, W. Product-related response to use of black models in advertising. Journal of Marketing Research, v. 8, n. 1, p. 107-109, 1971.

NOGUEIRA, O. Preconceito racial de marca e preconceito racial de origem: sugestão de um quadro de referência para a interpretação do material sobre relações raciais no Brasil. Tempo Social: Revista de Sociologia da USP, v. 19, n. 1, p. 287-308, 2007.

O'ROURKE, N; HATCHER, L; STEPANSKI, E. J. A step-by-step approach to using SAS for univariate and multivariate statistics. 2. ed. Cary: SAS Institute Inc, 2005.

QUALLS, W; MOORE, D. Stereotyping effects on consumers' evaluation of advertising: impact of racial differences between actors and viewers. Psychology and Marketing, v. 7, n. 2, p. 135-151, 1990.

REIDENBACH, R. E; MCCLEARY, K. W. Advertising and male nudity: an experimental investigation. Academy of Marketing Science Journal, v. 11, n. 4, p. 444-454, 1983. 
RODRIGUES, J. C. O negro brasileiro e o cinema. Rio de Janeiro: Pallas, 2001.

SOUZA, T. P. Veiculação da imagem do negro na propaganda: uma visão do consumidor universitário. Revista de Administração da Unime, v. 4, n. 4, p. 1-47, 2005.

STAFFORD, J; BIRDWELL, A; VAN TASSEL, C. Integrated advertising-white backlash. Journal of Advertising Research, v. 10, n. 2, p. 15-20, 1970.

STROZENBERG, I. O apelo da cor: percepções dos consumidores sobre as imagens da diferença racial na propaganda brasileira. Comunicação, Midia e Consumo, v. 2, n. 4, p. 199-220, 2008.

TELLES, E. Racismo à brasileira: uma nova perspectiva sociológica. Rio de Janeiro: Relume Dumará, 2003.

TRINDADE, L. V. Participação e representação social de indivíduos afrodescendentes retratados em anúncios publicitários de revistas: 1968-2006. 2008. 211 f. Tese de Doutorado, Programa de Mestrado e Doutorado em Administração, Universidade Nove de Julho, São Paulo, 2008.

TURRA, C; VENTURI, G. Racismo cordial: a mais completa análise sobre o preconceito de cor no Brasil. São Paulo: Ática, 1995.

WHITTLER, T. The effects of actors' race in commercial advertising: review and extension. Journal of Advertising, v. 20, n. 1, p. 54-60, 1991.

WHITTLER, T; CALANTONE, R; YOUNG, M. Strength of ethnic affiliation: examining black identification with black culture. The Journal of Social Psychology, v. 131, n. 4, p. 461-467, 1991.

WHITTLER, T; SPIRA, J. Model's race: a peripheral cue in advertising messages? Journal of Consumer Psychology, v. 12, n. 4, p. 291-301, 2002.

WILL, J; COBB, S; CHENEY, T. Florida's changing rainbow: identifying emerging markets through the examination of racial composition and demographic change in Florida. Population Research and Policy Review, v. 27, n. 5, p. 497-514, 2008.

WILSON, B; SPARKS, R. "It's gotta be the shoes": youth, race, and sneaker commercials. Sociology of Sport Journal, v. 13, n. 4, p. 398-427, 1996. 